Kwartalnik Młodych Muzykologów UJ

nr 47 (4/2020), s. 215-228

DOI 10.4467/23537094KMMUJ.20.024.13210

www.ejournals.eu/kmmuj

(iD) https://orcid.org/oooo-0oo3-1775-4880

\title{
Luiza Zapiór
}

UNIWERSYTET WARSZAWSKI

\section{Tradycje muzyczne Żydów aszkenazyjskich a Radical Jewish Culture: definicje i treści dawnej i współczesnej muzyki żydowskiej}

\section{Abstract}

Jewish Music and Radical Jewish Culture: A Brief Outline of the Definitions and Content of Jewish Music in the Past and Nowadays

The main purpose of the article is to describe John Zorn's approach to klezmer music and Jewish music tradition in general. The text was split into shorter paragraphs. The first part of the article is dedicated to providing an overview of the problems concerning the definition of Jewish music. The second part focuses on analysing klezmer motifs in John Zorn's selected works and Jewish symbols present in the visual layer connected with his works. The last paragraph contains a summary and conclusions. 


\section{Keywords}

Jewish music, instrumental music, John Zorn, Radical Jewish Culture, contemporary music

\section{Wstęp}

Muzyka żydowska nieprzerwanie stanowi przedmiot zainteresowania artystów i badaczy. Jednymi kieruje potrzeba zrozumienia przeszłości i powrotu do własnej tradycji, innych, przyglądających się jej z pozycji outsidera, pociąga jej tajemniczość i odmienność. Niezależnie jednak od motywów zagadnienie to skłania wciąż do refleksji - począwszy od pytań o definicję i początki, a skończywszy na koncepcjach dotyczących jej miejsca we współczesnej rzeczywistości.

W niniejszej pracy głównym przedmiotem przemyśleń staną się pytania odnoszące się do drugiego bieguna problemu. Dotyczą one przede wszystkim czasów współczesnych i wyzwań, które przynosi teraźniejszość. Kontekstem dla tych przemyśleń będzie wybrana twórczość amerykańskiego kompozytora i instrumentalisty Johna Zorna, inicjatora ruchu Radical Jewish Culture i założyciela wytwórni płytowej Tzadik, która skupia twórców wykonujących oraz tworzących muzykę inspirowaną tradycją klezmerską i nawiązującą do niej.

Artykuł podzielono na dwie części. Pierwsza z nich stanowi zarysowanie problematyki definicji i badania historii muzyki żydowskiej, druga natomiast poświęcona jest klezmerskim motywom w wybranych utworach Johna Zorna oraz założeniom ruchu Radical Jewish Culture. Poddany analizie został też problem wykorzystania symboliki żydowskiej na okładkach płyt.

Do literatury traktującej o Radical Jewish Culture w perspektywie muzycznej zaliczyć można artykuł Michaela Cuthberta Free improvisation: John Zorn and the Construction of Jewish Identity through Music, w którym autor dokonał interesujących analiz formalnych i kontekstualnych. Na uwagę zasługuje też książka John Zorn: Tradition and Transgression Johna Bracketta, która bada między innymi rolę tradycji żydowskiej w twórczości kompozytorskiej Johna Zorna. Ważną publikacją jest również New York Noise. Radical Jewish Music and the Downtown Scene Tamar Barzel, w której autorka analizuje dzia- 
łalność ruchu Radical Jewish Culture zarówno od strony muzycznej, ale również socjologicznej i kulturoznawczej. Jednak w literaturze polskojęzycznej kwestia ta nie została jednak rozwinięta wyczerpująco i wymaga dogłębnych badań interdyscyplinarnych.

Celem niniejszej pracy jest zwrócenie uwagi polskiego czytelnika na twórczość Zorna oraz na przeobrażenia tradycyjnej kultury muzycznej Żydów aszkenazyjskich w Ameryce ostatnich dekad na przykładzie aktywności stworzonego przez niego ruchu Radical Jewish Culture ${ }^{1}$.

\section{Definicje muzyki żydowskiej}

Czym jest muzyka żydowska? Co sprawia, że daną melodię klasyfikujemy jako żydowską? Czy można oddzielić rolę muzyki żydowskiej od kwestii ideologicznych? Próba odpowiedzi na te pytania jest źródłem nieustających dyskusji. Według Curta Sachsa muzyka żydowska to „muzyka tworzona przez Żydów, dla Żydów, jako żydowska²". Choć definicja zaprezentowana na I Międzynarodowym Kongresie Muzyki Żydowskiej w Paryżu w 1957 roku jest często przytaczana, to nie sposób nie zauważyć pewnych jej wad. Przedstawione w niej kryterium narodowe dobrze wpisuje się w ramy ideologii syjonistycznej, jednak w kontekście rozważań muzykologicznych przysparza ono problemów. Dylematy te celnie opisuje Alexander Knapp:

Czy coś skomponowane nie przez Żyda, nie dla żydowskich odbiorców, nie jako żydowskie ipso facto, nie jest muzyką żydowską? Czy możemy stwierdzić tylko przez posłuchanie Uwertury na tematy hebrajskie Prokofiewa lub cyklu pieśni $Z$ żydowskiej poezji ludowej, że dzieła te były napisane przez kompozytorów, którzy nie byli Żydami, a którzy mimo to czuli głębokie uznanie i zrozumienie dla tradycji aszkenazyjskiej ${ }^{3}$ ?

1 Wszystkie tłumaczenia, o ile nie zaznaczono inaczej, zostały wykonane przez autorkę.

2 M.B. Edelman, Discovering Jewish Music, The Jewish Publication Society, Philadelphia 2003, s. 9.

3 A. Knapp, Conceptualizing "Jewish Art Music" While Standing on One Leg: A Scholar's Dilemma, „Journal of the American Musicological Society”, 2012, r. $65, \mathrm{nr} 2$, s. 565 . 
Alternatywą dla poglądu Sachsa wydaje się stanowisko Hugo Weisgalla - zauważa on, że "nie ma specyficznej, obiektywnej muzycznej jakości, która czyniłaby muzykę żydowską bądź nie"4. Choć słowa te nie dają nam jednoznacznej odpowiedzi na pojawiające się pytania, to zwracają uwagę na problem bezstronności. Można uznać, że muzyka sama w sobie, obiektywnie, nie posiada tożsamości. W tym kontekście głębokiego sensu nabiera uwaga Judy Cohena o konieczności świadomości tego, że badając muzykę żydowską, nawiązujemy zawsze do czyjejś narracji:

\footnotetext{
Josef Singer rzetelnie skodyfikował skale synagogalne w 1886, Abraham Cwi Idelsohn połączył je $\mathrm{z}$ arabskim stylem maqam i dopasował do nich zasady harmonii na początku dwudziestego wieku, Isadore Freed wprowadził je w kontekst muzyki zachodniej w 1958 roku, a Eric Werner zaznaczył ich starożytne pochodzenie jako wyznacznik żydowskiej tożsamości [...]. Sposób, w jaki badacze współcześnie postrzegają problem, w dużej części zależy od ideologii, polityki i arbitralnych decyzji tych, którzy w przeszłości zdobyli status autorytetów w dziedzinie muzyki żydowskiej ${ }^{5}$.
}

Należy także zauważyć, że istnienie diaspory syjonistycznej, obejmującej wszystkie kontynenty, sprawia, że muzyka żydowska jest różnorodna i wielokulturowa, ale w konsekwencji trudna do ujęcia w sposób całościowy. Brak też źródeł pisanych. Przekazywanie melodii drogą ustną sprawnie funkcjonowało przez setki lat (chazani nie pobierali formalnej edukacji muzycznej i nie uczyli się notacji muzycznej aż do połowy XIX wieku) ${ }^{6}$. W przypadku muzyki ludowej oralna forma przekazywania wiedzy była powszechna, nie wyróżniała się więc na tle innych kultur muzycznych.

Wraz z nadejściem Haskali i proponowanych przez nią zmian, takich jak większa integracja z ludnością nieżydowską, skupienie uwagi także na świeckiej, a nie jedynie religijnej edukacji, czy wzrost zainteresowania historią żydowską, pojawiła się potrzeba zbudowania żydowskiej tożsamości o charakterze świeckim. Okres ten w kontekście kultury

4 Tamże, s. 566.

5 J.M. Cohen, Whither Jewish Music? Jewish Studies, Music Scholarship, and the Tilt between Seminary and University, Cambridge UP, Cambridge 2008, s. 31.

6 P.C. Kim, Transmission of Music in the Hebrew Tradition, „The Bulletin of Historical Research in Music Education" 1997, r. 19, nr 1, s. 44. 
muzycznej daje podwaliny pod twór, który w ostatnich dekadach XIX wieku zostanie nazwany muzyką żydowską ${ }^{7}$. Jedną z przyczyn tego zjawiska opisał szczegółowo Philip V. Bohlman:

\footnotetext{
Przed epoką nowoczesności [...] „muzyka” nie istniała jako estetycznie autonomiczny przedmiot w społeczności żydowskiej. W ścisłym sensie wszystko w synagodze było muzyką: modlitwa, Tora i Haftara, śpiewne recytacje (cantillation), praktyki rytualne i liturgiczne, toteż nie sposób było ograniczyć ją do jakiejkolwiek kategorii gatunkowej czy stylowej [...]. Cykliczny charakter muzycznych praktyk połączył, jak się wydaje, muzykę z rytuałem i nie pozwolił jej przepłynąć do historii „zewnętrznej” wobec temporalnego świata synagogi ${ }^{8}$.
}

Można stwierdzić więc, że muzykę żydowską w pewnym momencie historii „wynaleziono”, czy też zaczęła istnieć ona także poza kontekstem liturgicznym. Niewątpliwie posiadanie własnej muzyki stanowi też ważną część tożsamości narodowej, a ostatnie dekady XIX wieku były okresem rozwoju syjonizmu. Niezależnie jednak od kwestii ideologicznych czy filozoficznych można zauważyć, że sposób, w jaki definiowana jest muzyka żydowska, zależy niewątpliwie od samego definiującego. Kwestie takie jak religia czy polityka, a przede wszystkim wciąż zmieniająca się rzeczywistość, wpływają na to, czym w danym momencie jest muzyka żydowska.

\section{Od tradycyjnej do współczesnej kultury żydowskiej: omówienie wybranych motywów muzycznych i kulturowych w projektach Johna Zorna}

Zagłada sprawiła, że po II wojnie światowej muzyka żydowska straciła wielu kontynuatorów. Wspomnieć należy przy tym, że w Stanach Zjednoczonych, już od czasów przedwojennych, żydowscy imigranci kontynuowali swoją aktywność muzyczną. Łączyli oni własne tradycje z muzyką poznaną w Ameryce Północnej. Stworzono w ten sposób nowy rodzaj ekspresji muzyki żydowskiej, która zaczęła istnieć

7 P.V. Bohlman, Muzyka żydowska i nowoczesność, tłum. Z. Skowron, „Przegląd Muzykologiczny" 2006, nr 6, s. 185.

8 Tamże, s. 20. 
w odniesieniu do muzyki amerykańskiej. Artystą zainteresowanym jej rozwojem i umiejscowieniem w kontekście współczesności był John Zorn - postać, której nie sposób pominąć, poruszając temat nowej muzyki żydowskiej. Założona przez niego w 1995 roku wytwórnia płytowa Tzadik jest największym i najbardziej rozpoznawalnym wydawnictwem zajmującym się muzyką żydowską we współczesnym, często postrzeganym jako awangardowe, ujęciu. Przykłady z jego twórczości stanowią więc reprezentacyjny przykład tego, jak muzyka określana jako żydowska może funkcjonować we współczesnej rzeczywistości.

W Polsce i Europie do tej pory nie powstała żadna wytwórnia, którą można by porównać do Tzadika pod względem skali i profilu działania. W związku z tym nowe interpretacje muzyki żydowskiej, pochodzące chociażby z Polski, są porównywane ze sceną nowojorskiej Radical Jewish Culture i artystami z kręgu wspominanego wydawnictwa ${ }^{9}$. Niezależnie od tego, czy porównania te są celne czy nie, faktem jest istotna rola działalności Johna Zorna w rozwoju nowej muzyki żydowskiej.

Jego zainteresowanie syjonistyczną tradycją przypadło na początek lat dziewięćdziesiątych. Był on już wtedy prawie czterdziestoletnim twórcą $\mathrm{z}$ ugruntowaną $\mathrm{w}$ świecie muzycznym pozycją, miał doświadczenie wykonawcze oraz kompozytorskie związane między innymi z muzyką jazzową i klasyczną. Jak sam stwierdził, zwrot w stronę żydowskiej kultury spowodowany było częstą współpracą z muzykami tego pochodzenia, antysemityzmem, z którym spotykał się, koncertując w innych krajach, a także brakiem poczucia przynależności do japońskiej kultury, którą interesował się we wcześniejszych latach ${ }^{10}$. Sam artysta również posiadał żydowskie korzenie. Istotne stały się dla niego także kwestie związane z potrzebą redefinicji muzyki żydowskiej i refleksja nad kierunkiem jej rozwoju:

Tradycja, historia i przeszłość zawsze zajmowały ważne miejsce w życiu Żydów, jednak równie ważne jest myślenie o przyszłości. Gdy jako ludzie dorastamy, naturalnym wydaje się, że nasza kultura powinna wzrastać

9 M. Schray, Shofar: Ha-Huncvot (Kilogramm 2013) ${ }^{* * * *}$, „Freejazzblog.com”, 08.07.2013, https://www.freejazzblog.org/2013/o7/shofar-ha-huncvot-kilogramm-2013.html [dostęp: 12.06.2020].

10 M.S. Cuthbert, Free improvisation: John Zorn and the Construction of Jewish Identity through Music, w: Studies in Jewish Musical Traditions. Insights from the Harvard Collection on Judaica Sound Recordings, red. K.K. Shelemay, Harvard College Library, Cambridge 2001, s. 10. 
wraz $\mathrm{z}$ nami. Tak jak jazz przeszedł drogę od dixielandu do free jazzu w przeciągu zaledwie kilku dekad, tak muzyka klasyczna odeszła od tonalności. Oczywistym dla mnie jest, że ten rodzaj wzrostu jest kluczowy dla muzyki żydowskiej ${ }^{11}$.

Pierwszą płytą, w której materiale Zorn zwrócił się w stronę swoich żydowskich korzeni, jest wydana w 1993 roku Kristallnacht. Jak zauważa Tamar Barzel, kompozycje zawarte na niej ukazują także zainteresowanie Zorna estetyką hardcore rocka i modernistycznymi technikami kompozytorskimi. Tak jak w przypadku poprzednich jego dzieł, miały na celu przytłoczyć odbiorcę poprzez ekstremalnie intensywne przeżycia, spotęgowane przez skorelowanie materiału muzycznego z obrazami, tytułami i treściami ${ }^{12}$. Jej nazwa nawiązuje do pogromu nazywanego Nocą Kryształową (niem. Kristallnacht), który miał miejsce w Niemczech w 1938 roku w nocy z 9 na 10 listopada. Noc Kryształowa postrzegana jest jako wydarzenie wprowadzające prześladowania w kolejny, najbardziej radykalny etap, nieuchronnie przybliżający nadchodzącą Zagładę.

Udział w tworzeniu Kristallnacht wzięli muzycy: pianista Anthony Coleman, basista Mark Dresser, skrzypek Mark Feldman, trębacz Frank London, gitarzysta Marc Ribot, perkusista William Winant i David Krakauer grający na klarnecie i klarnecie basowym. W otwierającej tę płytę kompozycji Shtetl wyraźne są nawiązania do tradycji klezmerskiej, stopione tu z praktyką improwizacji i elementami muzyki konkretnej. W przedstawionych poniżej transkrypcjach widoczne są klezmerskie inklinacje utworu. Solo na trąbce w wykonaniu Franka Londona oparte jest na charakterystycznej dla tego rodzaju muzyki skali Mi sze-Berach. Pojawia się też rotacyjny ruch melodii (transkrypcja 1) oraz typowe repetowanie pierwszego (transkrypcja 2) lub piątego stopnia skali (transkrypcja 3) na końcu fraz. W toku rozwoju utworu forma zaczyna być dekonstruowana przez stopniowe wprowadzanie dysonansów oraz odchodzenie od ustalonej metryczności na korzyść swobody ekspresji i wprowadzenia stylistyki freejazzowej. Pojawia się też element muzyki konkretnej w postaci fragmentu przemówienia Adolfa Hitlera.

11 J. Zorn, Radical Jewish Culture, „Tzadik.com”, 2006, http://www.tzadik.com/rjc info.html [dostęp: 22.06.2019].

12 T. Barzel, New York Noise: Radical Jewish Music and The Downtown Scene, Indiana UP, Bloomington 2015, s. 87. 


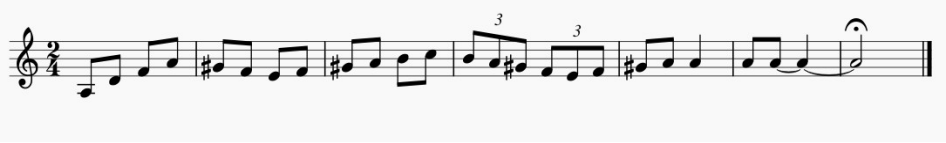

Transkrypcja 1. Shtetl, solo na trąbce w wykonaniu Franka Londona. Źródło: J. Zorn, Shtetl, wyk. F. London, w: Kristallnacht, Tzadik, Nowy Jork 1993, 0:01-0:07

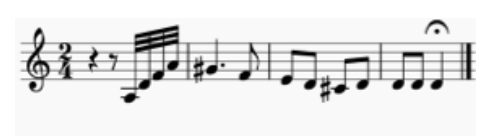

Transkrypcja 2. Shtetl, solo na trąbce w wykonaniu Franka Londona. Źródło: J. Zorn, Shtetl, wyk. F. London, w: Kristallnacht, Tzadik, Nowy Jork 1993, 0:07-0:14

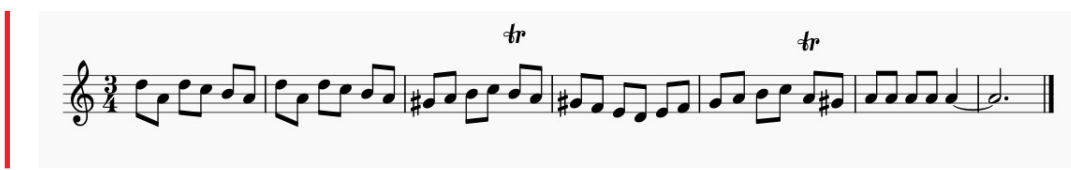

Transkrypcja 3. Shtetl, solo na trąbce w wykonaniu Franka Londona. Źródło: J. Zorn, Shtetl, wyk. F. London, w: Kristallnacht, Tzadik, Nowy Jork 1993, 0:15-0:24

Tematyka Zagłady, wykorzystanie elementów muzyki konkretnej, trzyczęściowa budowa odnosząca się do trzech wymiarów czasowych może nasuwać skojarzenia z utworem Different Trains Steve’a Reicha ${ }^{13}$. Podobnie jak dzieło Zorna kompozycja ta podzielona jest na trzy części odnoszące się kolejno do trzech płaszczyzn czasowych: tego, co działo się przed, w trakcie i po II wojnie światowej. Sam Zorn kwestię rozumienia czasu i historii w swoim utworze wyjaśnia tak:

Chciałem stworzyć kompozycję opierającą się na mojej obserwacji żydowskich doświadczeń. Nie tylko Holocaustu, ale też tego, co działo się przed nim, tego co działo się później, czyli o narodzinach Państwa Izrael, problemach dotyczących zbyt daleko posuniętej ortodoksji, o dzisiejszych Żydach i o tym, do czego zmierzamy. Jednak potem chciałem zrobić coś, co nie opierałoby się na historii bólu i cierpienia, ale na przyszłości i na tym, jak świetlana i piękna może ona być14.

13 M.S. Cuthbert, Free improvisation..., dz. cyt., s. 11.

14 J. Zorn, Scene by scene, rozm. L. Blumenfeld, „Jazziz” 1999, nr 8, s. 12. 
Należy zaznaczyć, że muzyka klezmerska była jednym z wielu źródeł inspiracji dla Johna Zorna w przypadku omawianej płyty. Utwory z płyty Kristallnacht nawiązują chociażby do muzyki synagogalnej, ekspresji freejazzowej, muzyki konkretnej czy techniki game piece, polegającej na oparciu utworu na schematach kompozycyjnych zgodnie z teorią gier (utwór Tikkun). Utwory te niewątpliwie zasługują na szczegółową analizę, która skupiałaby się na opisaniu wykorzystanych technik kompozytorskich. Utwór Shtetl jednak w największym stopniu nawiązuje do muzyki klezmerskiej i, zważywszy na tematykę niniejszego artykułu, jest reprezentatywnym przykładem utworu inspirowanego jednym z nurtów muzycznych pochodzących z bogatej i różnorodnej tradycji muzyki aszkenazyjskiej.

Płyta Kristallnacht stała się pierwszym krokiem do realizacji kolejnego założenia, którego celem było ukazanie tej muzyki jako rozwijającej się i ważnej części współczesnej żydowskiej tożsamości oraz kultury. Środkiem do realizacji tego celu miała być skomponowana w 1993 roku pierwsza z trzech części Masady. Jest to zbiór krótkich kompozycji nawiązujących do różnych tradycji muzyki żydowskiej. Całkowita liczba kompozycji zawartych we wszystkich częściach Masady wynosi 613, czyli dokładnie tyle, ile w judaizmie wyróżnionych jest micw; tytuły utworów pochodzą zaś z języka hebrajskiego. Kompozycje wchodzące w skład Masady bywają opisywane jako połączenie muzyki klezmerskiej i free jazzu w stylu wykonawczym Ornetta Colemana ${ }^{15}$. Nie mają one określonego składu instrumentalnego ani konkretnej aranżacji. Samo wykonanie odbywa się więc na podobnych zasadach, co realizacja standardu jazzowego, który co prawda narzuca konkretną harmonię i rys melodyczny, ale resztę zostawia w gestii wykonawcy. Uwagę zwraca też, często niezauważane, wyjście poza muzykę klezmerską i sięgnięcie do muzyki sefardyjskiej czy arabskiej. Masada jest więc zbiorem, który przedstawia muzykę żydowską w sposób różnorodny, a podejście do roli wykonawcy $\mathrm{w}$ procesie interpretacji pozwala mu na przedstawienie jej $\mathrm{w}$ taki sposób, w jaki ją rozumie i sobie ją wyobraża.

Masada miała również dowodzić, że muzyka żydowska może istnieć poza muzyką klezmerską, jednak, zważywszy na jej recepcję, ciężko jednoznacznie stwierdzić, czy faktycznie udało się to osiągnąć, co zauważa i podkreśla sam Zorn:

15 S. Rogovoy, The Essential Klezmer, Algonquin Books, New York 200o, s. 145. 
[...] jedyną rzeczą, która bardzo mnie zaskakuje, i która jest symbolem tego, jak bardzo ograniczony zasięg mają uszy muzyków, jest sposób w jaki krytycy to opisują «klezmer spotyka Ornetta!». Oczywiście, jest w tym element klezmerski. Oczywiście, jest w tym Ornette. Ale jest w tym także wiele innych inspiracji $[\ldots]^{16}$

Elementy żydowskie w jego twórczości nie zawsze związane są jedynie z muzyką per se. Tytuły utworów w języku hebrajskim, okładki płyt wykorzystujące żydowskie motywy czy nawiązywanie do symbolicznych znaczeń liczb również wpływają na fakt, że w odbiorze klasyfikowane są właśnie jako żydowskie.

Interesującym przykładem wykorzystania symboliki liczbowej może być utwór Sacred Rites of the Left Hand Path, w którym John Brackett dopatruje się inklinacji kabalistycznych. Ostinato, na którym oparta jest kompozycja, utrzymane jest w metrum 13/8. Zgodnie z zasadami gematrii liczba 13 odpowiada wartości liczbowej słowa „miłość” (הבהא) i „jeden" (דחא). Może świadczyć to o religijnym wymiarze utworów, wszak za słowem ,jeden” w rodzaju męskim w tradycji żydowskiej często kryje się Bóg, Adonai Echad ${ }^{17}$. Trudno jednak rozstrzygnąć, czy opisana obserwacja ma jakiś związek z intencjonalnym działaniem kompozytora, czy może jest dziełem pewnej nadinterpretacji.

Symbolika żydowska pojawia się też na okładkach płyt - Masada Guitars (ilustracja 1) przedstawia układ rąk, nawiązujący do kabalistycznego Drzewa Życia wraz z jego dziesięcioma sefirot.

Na okładce The Unknown Masada (ilustracja 2) pojawia się natomiast jad ze słowem דמ (dosł. nauka, wiedza) w tle, prawdopodobnie symbolizujący naukę i mądrość pochodzącą z Tory. Można wnioskować, że symbole zaprezentowane na okładkach czy tytuły kompozycji nie mają odniesień do samych utworów, a służą raczej stworzeniu odpowiedniej impresji u odbiorcy i nadaniu utworom autentyzmu.

16 J. Zorn, dz. cyt., s. 13.

17 J. Brackett, John Zorn: Tradition and Transgression, Indiana UP, Bloomington 2008, s. 68 . 
Luiza Zapiór, Tradycje muzyczne Żydów aszkenazyjskich...

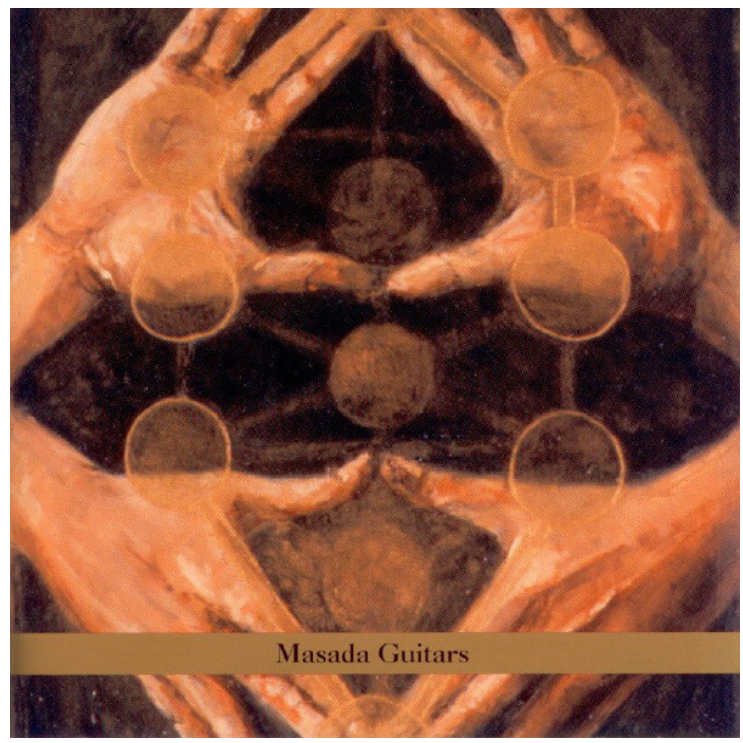

Ilustracja 1. Okładka płyty Masada Guitars. Źródło: http://www.allmusic.com/ album/masada-guitars-mwooo0234597 [dostęp: 16.01.2019]

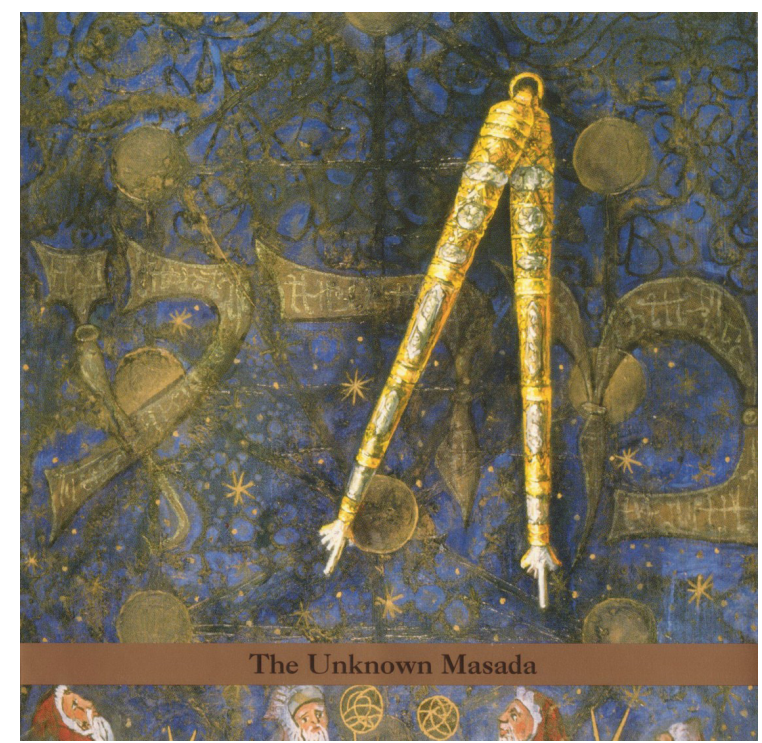

Ilustracja 2. Okładka płyty The Unknown Masada. Źródło: https://www.discogs. com/John-Zorn-The-Unknown-Masada/release/529218 [dostęp: 16.01.2019] 


\section{Podsumowanie}

Twórczość Johna Zorna związaną z muzyką żydowską można podzielić na dwa etapy. Pierwszy, związany z Kristallnacht, to wspomnienie przeszłości, tragicznych czasów Zagłady i początków Państwa Izrael, które nawiązuje do wydarzeń historycznych, ale z drugiej strony wyrażone zostaje nowoczesnym językiem muzycznym. Można odczytywać to jako zapowiedź kolejnego etapu, reprezentowanego przez Masadę, którego celem było spojrzenie ku przyszłości i wprowadzenie muzyki żydowskiej w nowy wiek. Nie ignorując różnorodności tradycji, dała ona wykonawcom możliwość samodzielnego odkrycia, czym jeszcze może być muzyka żydowska.

Zornowi niewątpliwie udało się uchwycić i uczynić niedefiniowalność żydowskiej muzyki częścią swojej teorii. Rozwiązaniem w tym przypadku nie jest ustalenie konkretnych reguł, cech i warunków do spełnienia, ale akceptacja dynamiki i płynności istoty muzyki żydowskiej. Taki sposób rozumienia jest reakcją na skomplikowane realia judaistycznej kultury po II wojnie światowej i pytanie o miejsce, jakie powinna zajmować w niej muzyka. Niewątpliwie potrzebna jest w przyszłości analiza utworów nawiązujących do żydowskich tradycji muzycznych innych niż klezmerska. Twórczość i założenia Johna Zorna odgrywają też istotną rolę w procesie uniwersalizacji muzyki żydowskiej, w wyniku którego muzyka konkretnej grupy staje się powszechnym źródłem artystycznych inspiracji. Trafnie ujmują te zmiany trawestujące dyskursywną definicję Kurta Sachsa słowa Tamary Sztymy: „[...] nowa muzyka żydowska jest dziś tworzona głównie przez nie-Żydów, także dla nie-Żydów i staje się częścią sfery uniwersalnej”"18.

18 T. Sztyma, Duma, zabawa i milczenie, rozm. I. Świerkocka, „Dwutygodnik” 2017, $\mathrm{nr}$ 206, http://www.dwutygodnik.com/artykul/6988-duma- zabawa-i-milczenie. html [dostęp: 05.08.2019]. 


\section{Bibliografia}

\section{Opracowania}

Barzel T., New York Noise: Radical Jewish Music and The Downtown Scene, Indiana UP, Bloomington 2015.

Bohlman P.V., Muzyka żydowska i nowoczesność, tłum. Z. Skowron, „Przegląd Muzykologiczny” 2006, nr 6, s. 185-207.

Brackett J., John Zorn: Tradition and Transgression, Indiana UP, Bloomington 2008.

Cohen J., Whither Jewish Music? Jewish Studies, Music Scholarship, and the Tilt Between Seminary and University, Cambridge UP, Cambridge 2008.

Cuthbert M., Free improvisation: John Zorn and the Construction of Jewish Identity through Music, w: Studies in Jewish Musical Traditions. Insights from the Harvard Collection of Judaica Sound Recordings, red. K.K. Shelemay, Harvard College Library, Cambridge 2001.

Edelman M., Discovering Jewish Music, The Jewish Publication Society, Philadelphia 2003.

Knapp A., Conceptualizing „Jewish Art Music” While Standing on One Leg: A Scholar's Dilemma, „Journal of the American Musicological Society" 2012, r. 65, nr 2, s. 557-592.

Kim P. C., Transmission of Music in the Hebrew Tradition: Learning from the Songs of the Synagogue, „The Bulletin of Historical Research in Music Education" 1997, r. 19, nr 1, s. 40-51.

Rogovoy S., The Essential Klezmer. A Music Lover's Guide to Jewish Roots and Soul Music, from the Old World and the Jazz Age to the Downtown Avant-garde, Algonquin Books of Chapel Hill, New York 2000.

Zorn J., Scene by scene, rozm. L. Blumenfeld, „Jazziz”1999, nr 8, s. 12-13.

\section{Źródła internetowe}

Schray M., Shofar: Ha-Huncvot (Kilogramm, 2013) ${ }^{* * * *}$, 08.07.2013, https://www.freejazzblog.org/2013/o7/shofar-ha-huncvot-kilogramm-2013.html [dostęp: 12.06.2020]. 
Sztyma T., Duma, zabawa i milczenie, rozm. I. Świerkowska, https:// www.dwutygodnik.com/artykul/6988-duma-zabawa-i-milczenie. html?print=1 [dostęp: 05.08.2019].

Zorn J., Radical Jewish Culture, http://www.tzadik.com/rjc info.html [dostęp: 22.06.2019]. 